\title{
Sternal malunion mimicking an artifact
}

\author{
Banu Yoldas, Ozgur Oner, Tayfun Yoldas
}

\section{CASE REPORT}

An 85-year-old female was referred to our hospital with right hip pain following a fall at home. She was hospitalized to the department of orthopedic surgery for an operation for trochanter major fracture. She had hypertension and a history of a motor vehicle accident about 10 years ago.

During her preoperative evaluation, chest X-ray showed an increased density like an anterior mediastinal tumor. The patient was referred to thoracic surgery and on physical examination there was a fixed, hard sternal mass about $10 x 10 \mathrm{~cm}$ in diameter. The motor vehicle accident on her anamnesis explained the findings on her X-ray and physical examination. A thoracic computed tomography scan well demonstrated the sternal malunion which mimicked a motion artifact (Figure 1, 2). The patient did not remember the details about the motor vehicle accident but she gave the information that she has been hospitalized at that time and as understood from her anamnesis she was treated conservatively. An operation was planned for sternal

Banu Yoldas ${ }^{1}$, Ozgur Oner ${ }^{2}$, Tayfun Yoldas ${ }^{3}$

Affiliations: ${ }^{1}$ Thoracic Surgery Department, Konya Education and Research Hospital, Konya, Turkey; ${ }^{2}$ Radiology Department, Konya Education and Research Hospital, Konya, Turkey; ${ }^{3}$ General Surgery Department, Kadinhani State Hospital, Konya, Turkey.

Corresponding Author: Banu Yoldas, Konya Education and Research Hospital, Thoracic Surgery Department, Konya, Turkey; Phone: +90 332 3236709; Fax: +90 332 3236723; Email: banuaktin@yahoo.com

Received: 29 March 2011

Accepted: 19 August 2011

Published: 01 September 2011 reconstruction but due to her advanced age, it was not done.

\section{DISCUSSION}

Operative treatment of sternal fractures is not an accepted routine approach. In general conservative treatment with painkillers is adequate. Surgical repair is for cosmetic reasons, difficulty in extubation due to an unstable flail chest and intractable pain $[1,2]$. Sometimes after conservative treatment, fracture union problems requiring surgical repair might be seen. After sternal fracture due to blunt trauma or some surgical procedures via sternotomy, the most important problems are debilitating pain, non-union or as reported in this case a "mal-union" [1-3]. There are different ways to repair such as T-shaped plate, linear or 8-hole titanium plates combined with or without bone matrix [1-4]. For our patient operative treatment was not considered due to her advanced age and concomitant disease.

\section{CONCLUSION}

We are of the opinion that surgical repair of sternal fractures should be kept in mind as an alternative treatment option especially for younger patients, keeping in mind such mal-union problems.

$* * * * * * * * *$

Yoldas B, Oner O, Yoldas T. Sternal malunion mimicking an artifact. International Journal of Case Reports and Images 2011;2(9):21-23.

$$
* * * * * * * * *
$$




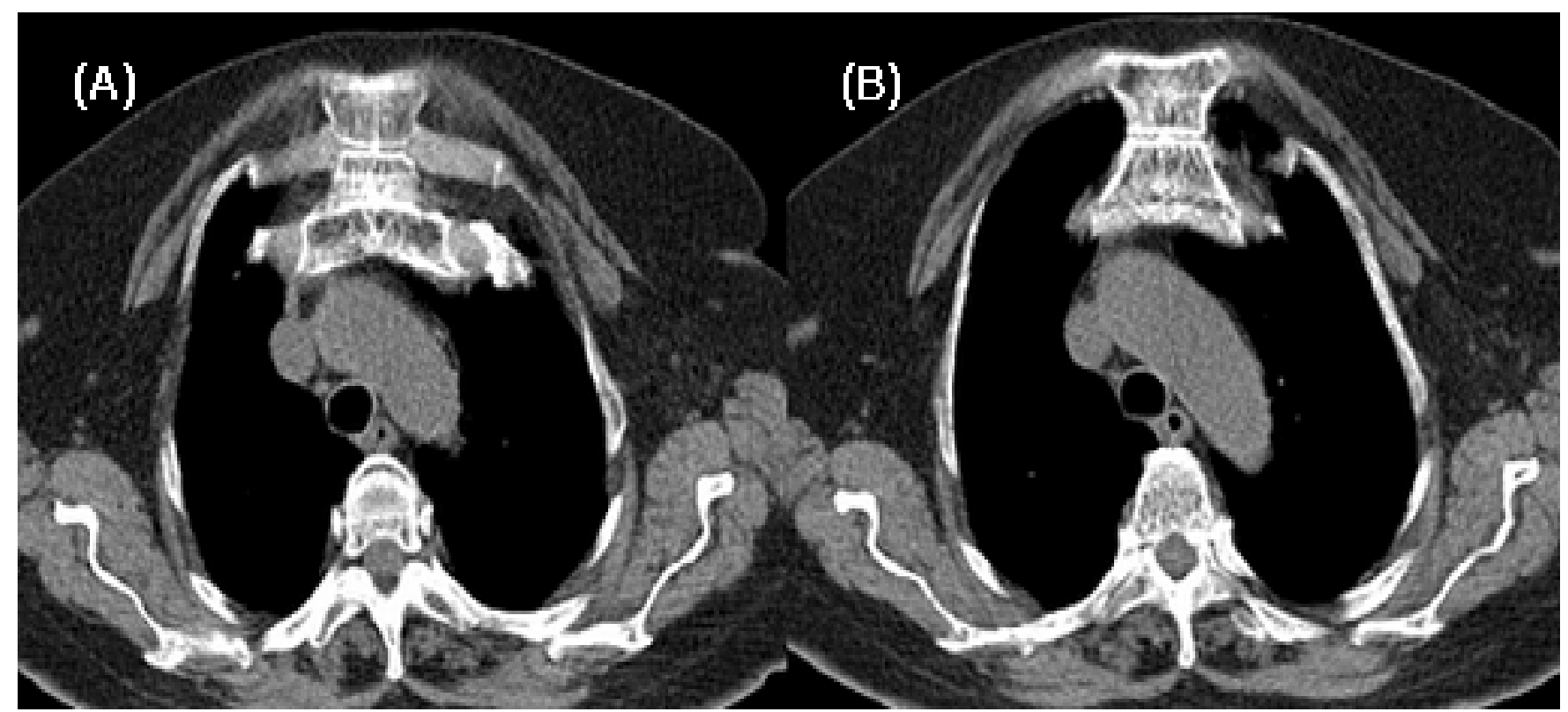

Figure 1: A) Due to malunion, sternum is seen to be doubled, like an artifact; B) Another section of computed tomography scan showing malunion.

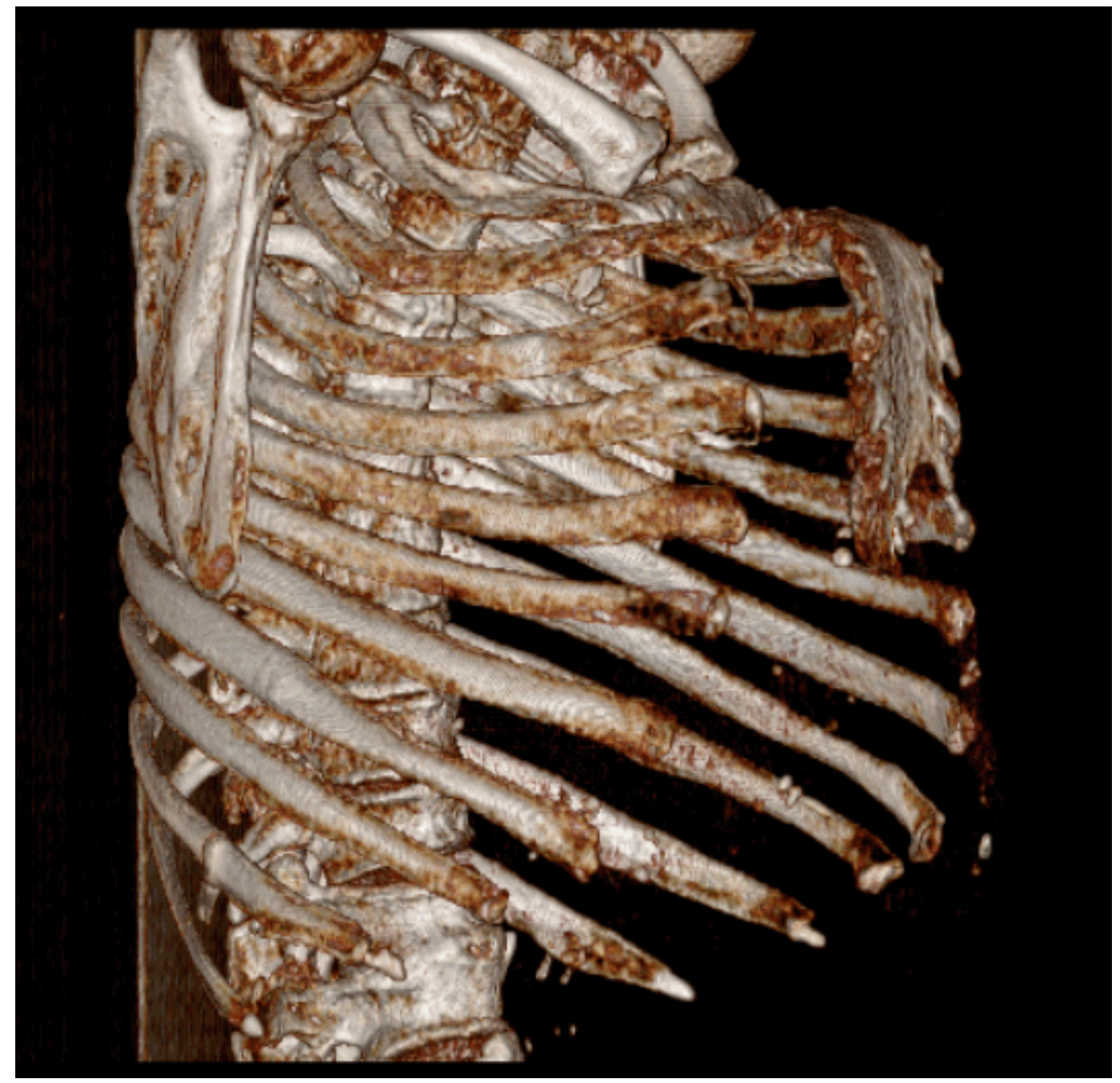

Figure 2: Three dimensional computed tomography demonstrating the malunion of sternum. 


\section{Acknowledgement}

We thank Dr. Daniel Allendorf for critical revision of the manuscript.

\section{Author Contributions}

Jason C. Paik - Conception and design, Acquisition of data, Analysis and interpretation of data, Drafting the article, Critical revision of the article, Final approval of the version to be published

Mary Elaine Killian - Conception and design, Acquisition of data, Analysis and interpretation of data, Drafting the article, Critical revision of the article, Final approval of the version to be published Jennifer J. Feldhaus - Conception and design, Acquisition of data, Analysis and interpretation of data, Drafting the article, Critical revision of the article, Final approval of the version to be published Carlos Estrada - Conception and design, Acquisition of data, Analysis and interpretation of data, Drafting the article, Critical revision of the article, Final approval of the version to be published

\section{Guarantor}

The corresponding author is the guarantor of submission.

\section{Conflict of Interest}

Authors declare no conflict of interest.

\section{Copyright}

(C) Banu Yoldas et al. 2011; This article is distributed under the terms of Creative Commons attribution 3.0 License which permits unrestricted use, distribution and reproduction in any means provided the original authors and original publisher are properly credited. (Please see www.ijcasereportsandimages.com /copyright-policy.php for more information.)

\section{REFERENCES}

1. Al-Qudah A. Operative treatment of sternal fractures. Asian Cardiovasc Thorac Ann. 2006;14:399-401.

2. Gallo DR, Lett ED, Conner WC. Surgical repair of a chronic traumatic sternal fracture. Ann Thorac Surg. 2006;81:726-8.

3. Schulz A, Faschingbauer M, Jürgens C. Sternal nonunion - development of a novel fixation device. Injury Extra. 2005;36:569-72.

4. Gandy KL, Moulton MJ. Sternal plating to prevent malunion of transverse sternotomy in lung transplantation. Ann Thorac Surg. 2008;86:1384-5. 